\title{
TRPA1 Contributes to Cold Hypersensitivity
}

\author{
Donato del Camino, ${ }^{1}$ Sarah Murphy, ${ }^{1}$ Melissa Heiry, ${ }^{1}$ Lee B. Barrett, ${ }^{4}$ Taryn J. Earley, ${ }^{3}$ Colby A. Cook, ${ }^{1}$ Matt J. Petrus, ${ }^{2}$ \\ Michael Zhao, ${ }^{1}$ Marc D’Amours, ${ }^{1}$ Nate Deering, ${ }^{1}$ Gary J. Brenner, ${ }^{5}$ Michael Costigan, ${ }^{4}$ Neil J. Hayward, ${ }^{1}$ \\ Jayhong A. Chong, ${ }^{1}$ Christopher M. Fanger, ${ }^{1}$ Clifford J. Woolf, ${ }^{4}$ Ardem Patapoutian, ${ }^{2,3}$ and Magdalene M. Moran ${ }^{1}$ \\ ${ }^{1}$ Hydra Biosciences, Inc., Cambridge, Massachusetts 02139, ${ }^{2}$ Genomics Institute of the Novartis Research Foundation, San Diego, California 92121, \\ ${ }^{3}$ Department of Cell Biology, The Scripps Research Institute, La Jolla, California 92037, ${ }^{4}$ F. M. Kirby Neurobiology Center, Children's Hospital Boston, and \\ Department of Neurobiology, Harvard Medical School, Boston, Massachusetts 02115, and 5Neuronal Plasticity Research Group, Department of Anesthesia \\ and Critical Care, Massachusetts General Hospital and Harvard Medical School, Charlestown, Massachusetts 02129
}

TRPA1 is a nonselective cation channel expressed by nociceptors. Although it is widely accepted that TRPA1 serves as a broad irritancy receptor for a variety of reactive chemicals, its role in cold sensation remains controversial. Here, we demonstrate that mild cooling markedly increases agonist-evoked rat TRPA1 currents. In the absence of an agonist, even noxious cold only increases current amplitude slightly. These results suggest that TRPA1 is a key mediator of cold hypersensitivity in pathological conditions in which reactive oxygen species and proinflammatory activators of the channel are present, but likely plays a comparatively minor role in acute cold sensation. Supporting this, cold hypersensitivity can be induced in wild-type but not Trpa1 ${ }^{-I-}$ mice by subcutaneous administration of a TRPA1 agonist. Furthermore, the selective TRPA1 antagonist HC-030031 [2-(1,3-dimethyl-2,6-dioxo-1,2,3,6-tetrahydro-7H-purin-7-yl)- $N$-(4isopropylphenyl)acetamide] reduces cold hypersensitivity in rodent models of inflammatory and neuropathic pain.

\section{Introduction}

TRPA1 is a calcium-permeable, nonselective cation channel of the transient receptor potential (TRP) superfamily expressed by sensory neurons in the dorsal root, trigeminal, and nodose ganglia (Story et al., 2003; Nagata et al., 2005). It is structurally and functionally unique, distinguished by a large $\mathrm{N}$-terminal cytoplasmic domain containing more than a dozen cysteine residues and 18 predicted ankyrin repeats (Jaquemar et al., 1999). Covalent modification of these cysteines by reactive compounds is sufficient to activate TRPA1 (Hinman et al., 2006; Macpherson et al., 2007a).

This unique mechanism of activation positions TRPA1 as a broad irritancy receptor for endogenous and exogenous reactive compounds. Indeed, TRPA1 is activated by a range of environmental irritants, including mustard oil, acrolein, formalin, and

\footnotetext{
Received May 20, 2010; revised Sept. 2, 2010; accepted Sept. 5, 2010.

This work was supported in part by National Institutes of Health Grant NS039518 (C.J.W.). We thank JoAnn Witek for tissue culture support and Jennifer Monsen for formulation work. We are grateful to Timothy Strassmaier, Xiaoguang Zhen, David Kimball, and David Clapham for helpful comments on this manuscript. D.d.C. performed electrophysiological experiments, designed experiments, analyzed data, wrote the paper, and supervised the project. S.M. performed electrophysiological experiments and analyzed data. M.H. performed electrophysiological experiments, analyzed data, and wrote the paper. L.B.B. designed and performed SNI experiments. T.J.E. and M.J.P. performed mouse in vivo experiments. C.A.C. performed rat in vivo experiments. M.Z. performed rat in vivo experiments. M.D. performed analytical work. N.D. performed electrophysiological experiments and wrote the paper G.J.B. performed SNI experiments. M.C. performed SNI experiments. N.J.H. wrote the paper. J.A.C. analyzed data and wrote the paper. C.M.F. analyzed data and wrote the paper. C.J.W. designed experiments, analyzed data, and wrote the paper. A.P. designed experiments, analyzed data, and wrote the paper.M.M.M. designed experiments, analyzed data, wrote the paper, and supervised the project.

C.J.W. is serving on the scientific advisory board of Hydra Biosciences (Cambridge, MA). D.d.C., S.M., M.H., C.A.C., M.Z., M.D., N.D., N.J.H., J.A.C., C.M.F., and M.M.M. are employees of Hydra Biosciences and receive options.

This article is freely available online through the $J$ Neurosci Open Choice option.

Correspondence should be addressed to Donato del Camino, Hydra Biosciences, Inc., 790 Memorial Drive, Cambridge, MA 02139. E-mail: ddelcamino@hydrabiosciences.com.

DOI:10.1523/JNEUROSCI.2580-10.2010

Copyright $\odot 2010$ the authors $\quad 0270-6474 / 10 / 3015165-10 \$ 15.00 / 0$
}

reactive oxygen species (Bang and Hwang, 2009). Furthermore, mice lacking functional TRPA1 exhibit diminished pain behaviors in response to mustard oil and formalin (Bautista et al., 2006; Kwan et al., 2006; Macpherson et al., 2007b; McNamara et al., 2007; Bessac et al., 2008).

In addition to exogenous agonists, TRPA1 responds to a variety of endogenous reactive compounds associated with pathological pain conditions, including 4-hydroxynonenal (4-HNE), cyclopentane prostaglandins, and reactive oxygen species such as hydrogen peroxide (Macpherson et al., 2007b; Trevisani et al., 2007; Andersson et al., 2008; Bessac et al., 2008; Cruz-Orengo et al., 2008; Materazzi et al., 2008; Taylor-Clark et al., 2008). These findings, combined with the observation that TRPA1 antagonists are analgesic in rodent models of pain, suggests that TRPA1 plays an important role in some pathological pain states (McNamara et al., 2007; Petrus et al., 2007; Eid et al., 2008).

Despite considerable study of the role of TRPA1 in cold pain, ambiguity remains (for review, see Kwan and Corey, 2009). Some groups report that noxious cold directly activates TRPA1 (Story et al., 2003; Sawada et al., 2007; Karashima et al., 2009), whereas others suggest that cold-induced elevation of intracellular calcium indirectly causes this activation (Zurborg et al., 2007). Studies using two independently made TRPA1 knock-out animals yield conflicting results, leaving the controversy unsettled (Bautista et al., 2006; Kwan et al., 2006; Karashima et al., 2009; Gentry et al., 2010).

We investigated the effect of cold on TRPA1 gating using electrophysiological recordings of both heterologously expressed rat TRPA1 and native TRPA1 from acutely isolated dorsal root ganglion (DRG) neurons. Temperature reductions activated recombinant TRPA1 in a calcium-independent fashion, although to a much lesser degree than treatment with chemical agonists. How- 
ever, even mild cooling substantially potentiated TRPA1 activation by reactive compounds.

We also examined the role of TRPA1 in cold sensation in vivo using behavioral assays. Cold responsiveness in wild-type (WT) but not Trpa1 ${ }^{-1-}$ mice was profoundly increased by subcutaneous injection of 4-HNE at a non-nocifensive concentration. In rats, selectively antagonizing TRPA1 with HC-030031 [2-(1,3dimethyl-2,6-dioxo-1,2,3,6-tetrahydro-7H-purin-7-yl)-N-(4isopropylphenyl) acetamide] reduced cold allodynia after nerve injury or inflammation, but had no effect on acute cold sensation. From these data, we postulate that TRPA1 is a critical mediator of cold hypersensitivity in pathological conditions. TRPA1 is thus a potential therapeutic target for pathological conditions accompanied by cold hypersensitivity.

\section{Materials and Methods}

Cells. Full-length rat TRPA1 cDNA was subcloned into pCDNA5/TO (Invitrogen). Stable clonal 293-T-REx cell lines (Invitrogen) were selected in $100 \mu \mathrm{g} / \mathrm{ml}$ hygromycin and grown according to the manufacturer's instructions.

Adult (9-12 week) rat DRGs were dissected and incubated at $37^{\circ} \mathrm{C}$ in $3 \mu \mathrm{g} / \mathrm{ml}$ collagenase type I (Worthington Biochemicals) in PBS for 30 min. The collagenase solution was removed, and the ganglia were incubated for $30 \mathrm{~min}$ at $37^{\circ} \mathrm{C}$ in $0.05 \%$ trypsin (Invitrogen) to dissociate the cells. The DRG preparation was resuspended and triturated in DMEM/ F12 medium containing 10\% FBS, $0.5 \%$ penicillin-streptomycin, and $0.5 \%$ glutamine. Neurons were cultured on poly-D-lysine (SigmaAldrich)-coated coverslips in this media. DRG neurons were used for electrophysiological recordings $16-24 \mathrm{~h}$ after plating.

Electrophysiology. All currents were recorded in whole-cell configuration using EPC-9 and EPC-10 amplifiers and Patchmaster software (HEKA). Patch pipettes had a resistance of $1.5-3 \mathrm{M} \Omega$, and $60-75 \%$ of the series resistance was compensated. Our standard pipette solution consisted of $140 \mathrm{~mm}$ CsAsp, $10 \mathrm{~mm}$ EGTA, 10 mm HEPES, $2.27 \mathrm{~mm} \mathrm{MgCl}$, $1.91 \mathrm{~mm} \mathrm{CaCl}_{2}, 4 \mathrm{~mm} \mathrm{MgATP}$, and $0.1-0.3 \mathrm{~mm} \mathrm{Na}_{2} \mathrm{GTP}$, with $\mathrm{pH}$ adjusted to 7.2 with $\mathrm{CsOH}$. In the experiments shown in Figure 2, $B$ and $C$, a different pipette solution was used containing $145 \mathrm{~mm} \mathrm{CsCl,} 10 \mathrm{~mm}$ HEPES, $10 \mathrm{~mm}$ EGTA, and $1 \mathrm{~mm} \mathrm{MgCl}_{2}, \mathrm{pH} 7.2$ adjusted with CsOH. The standard bath solution contained $150 \mathrm{~mm} \mathrm{NaCl}, 10$ mм HEPES, $10 \mathrm{~mm}$ glucose, $4.5 \mathrm{~mm} \mathrm{KCl,} 1 \mathrm{~mm}$ EGTA, $3 \mathrm{~mm} \mathrm{MgCl}_{2}$, with $\mathrm{pH}$ adjusted to 7.4 with $\mathrm{NaOH}$. In the recordings from primary dorsal root ganglia neurons shown in Figure 4 and in the indicated recordings from recombinant TRPA1 (Fig. 2 B; supplemental Figs. 3, 4, available at www.jneurosci.org as supplemental material), $2 \mathrm{~mm} \mathrm{CaCl}_{2}$ was added in place of EGTA and the concentration of $\mathrm{MgCl}_{2}$ was reduced to $1 \mathrm{~mm}$.

Data were collected either by continuous recordings at $-60 \mathrm{mV}$ or by applying voltage ramps from a holding potential of $0 \mathrm{mV}$ every $4 \mathrm{~s}$. Continuous recordings were collected at $400 \mathrm{~Hz}$ and digitally filtered off-line at $10 \mathrm{~Hz}$ for presentation. Voltage ramps were applied from -100 to $100 \mathrm{mV}$ over the course of $400 \mathrm{~ms}$, and data were collected at 10 $\mathrm{kHz}$ and filtered at $2.9 \mathrm{kHz}$. Inward and outward currents were analyzed from the ramps at -80 and $80 \mathrm{mV}$, respectively. Liquid junction potential correction was not used.

Solutions were switched using a gravity-fed continuous focal perfusion system. To achieve rapid temperature changes, two temperature control and perfusion systems were used simultaneously. For temperatures $\geq 22^{\circ} \mathrm{C}$, a Warner Instruments bipolar temperature controller (TC$344 \mathrm{~B})$ and inline heater (SHM-8) were used. For temperatures $<22^{\circ} \mathrm{C}$, a Warner Instruments temperature controller (CL-100) and thermal cooling module (TCM-1) were used. Final temperatures were confirmed using a thermistor (Voltcraft K101), with temperatures at the recorded cell estimated to be within $\pm 2^{\circ} \mathrm{C}$ of those reported. Although it was impossible to have a small enough thermistor in place to record the actual rate of temperature change during the experiments, we did record the rate of temperature change during a simulated experiment (i.e., without a cell present). These data are presented in supplemental Figure 1 (available at www.jneurosci.org as supplemental material), predicting that during recordings, the cell experiences each temperature change in $<15 \mathrm{~s}$.

Chemicals. Allyl isothiocyanate (AITC), acrolein, and Complete Freund's Adjuvant (CFA) were purchased from Sigma-Aldrich. 4-HNE was obtained from both Alexis Biochemicals and EMD Chemicals. HC030031 was obtained from ChemBridge. All reagents were prepared fresh daily.

In vivo studies. All experiments involving rats were conducted in accordance with approved Institutional Animal Care and Use Committee protocols from the relevant institutions. In addition, all experiments were performed in accordance with the Society for Neuroscience Policies on the Use of Animals and Humans in Neuroscience Research. A 15 $\mathrm{mg} / \mathrm{ml}$ homogenous suspension of HC-030031 was achieved by homogenization in $0.5 \%$ 4000-centipoises methyl cellulose. Male Sprague Dawley rats (Charles River) received a single intraperitoneal injection of 150 $\mathrm{mg} / \mathrm{kg}$ HC-030031 or vehicle $(0.5 \%$ methyl cellulose) $60 \mathrm{~min}$ before testing. Dose solution concentration was confirmed by analysis with liquid chromatography with tandem mass spectrometry.

4-HNE-induced thermal hyperalgesia. All experiments involving mice were performed blind with respect to the genotype. Behavioral analysis was conducted on male and female mice 8-12 weeks of age. TRPA1 mutant strain mice were obtained from David P. Corey (Harvard Medical School, Boston, MA) and backcrossed to C57BL/6J for five generations. Animals were acclimated to their testing environment for at least 20 min before all experiments. Student's $t$ test was used for all statistical calculations.

A clear Plexiglas chamber containing a Peltier-cooled cold plate, temperature controller, and heat sink (TECA) was used to assess cold responses. Two independent temperature probes were used to confirm/ monitor the surface temperature of the plate. Before assays, mice were acclimated in an equivalent chamber at room temperature for $20 \mathrm{~min}$. Ten microliters of $5 \mathrm{~mm} 4$-HNE ( $50 \mathrm{nmol}$ ) was injected subcutaneously in both hindpaws. Mice were returned to their acclimation chambers for an additional $5 \mathrm{~min}$ before being placed on a $0^{\circ} \mathrm{C}$ cold plate. Nocifensive behavior was then assessed by counting the latency to the first jump, or the onset of brisk hindpaw lifts or flicking/licking of the hindpaws during a 5 min period.

Thermal hyperalgesia data were conducted using a Plantar Infrared (IR) Analgesia Meter (Hargreaves's Apparatus) from Ugo Basile. Mice were acclimated in a Plexiglas container for $1 \mathrm{~h}$, and averages of three exposures per paw, to IR intensity 20, were recorded.

Environmental cold and CFA-induced cold allodynia. On the day before injection of CFA, the rats were pretested/acclimated. Paw withdrawal latency (PWL) for each naive animal was determined. Briefly, each animal was carefully placed on a PE34 Cold Plate Analgesia Meter (IITC Life Science) set to $5^{\circ} \mathrm{C}$ and the built-in timer activated. The PWL was determined by observing the rat's behavioral response [i.e., a sustained period of stimulus avoidance (lifting/withholding) or a period of licking/biting]. Simultaneous PWL readings for both hindpaws were recorded. After each reading, the cold plate was wiped clean of urine and feces and confirmed to be at $5^{\circ} \mathrm{C}$ before a subsequent animal was tested.

The following day, $100 \mu \mathrm{l}$ of neat CFA was injected under the skin of the plantar surface of the left hindpaw under brief gaseous anesthesia. Two days later, the rats were again tested to confirm hyperalgesia: only animals that had a $40 \%$ difference in PWL between the injected and uninjected paw were included in the study.

Animals were then randomized so each group had similar mean PWLs. Animals were dosed with either vehicle or HC-030031 under blinded conditions (the operator of the cold plate was unaware as to what each animal had received). After the $45 \mathrm{~min}$ posttreatment time, the postdose PWL readings were taken. On completion of the PWL readings, the animals were killed.

Since we saw no effect of HC-030031 on the withdrawal latency of the uninjured rat paw to $5^{\circ} \mathrm{C}$, we also asked whether colder temperatures would unmask a potential role for TRPA1 in the detection of intense environmental cold, and exposed the rats to a cold plate at $-5^{\circ} \mathrm{C}$. In addition to measuring the PWL, we also counted the number of seconds of pain behavior over the course of $5 \mathrm{~min}$. A cutoff time of $5 \mathrm{~min}$ was set to limit any possible tissue damage resulting from excessive exposure to 
A
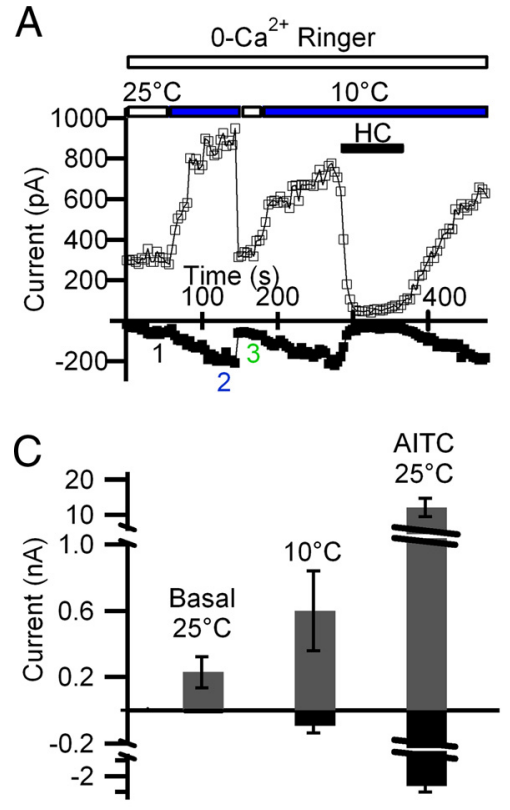

B

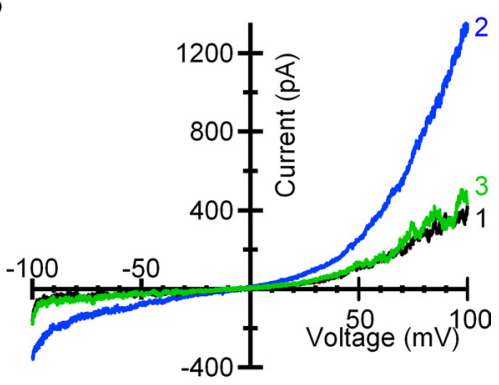

D

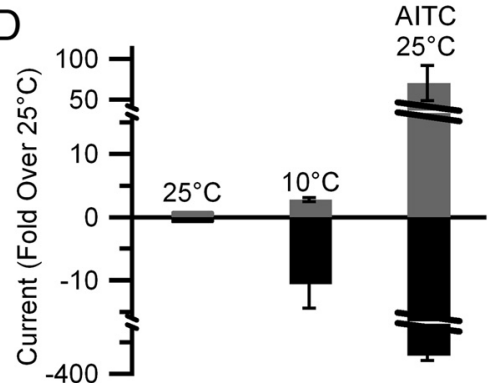

Figure 1. Cooling activates TRPA1 currents. $\boldsymbol{A}$, Whole-cell recording of an HEK-293 cell expressing rat TRPA1 (rTRPA1). A $400 \mathrm{~ms}$ ramp from -100 to $100 \mathrm{mV}$ was applied every $5 \mathrm{~s}$, and current measured at $-80 \mathrm{mV}$ (filled circles) and $+80 \mathrm{mV}$ (open circles) during each ramp is plotted as a function of time. The white and blue horizontal bars indicate the perfusion of bath solution at 25 or $10^{\circ} \mathrm{C}$, respectively. The $20 \mu \mathrm{M} \mathrm{HC}-030031$ at $10^{\circ} \mathrm{C}$ was added during the time indicated by the black horizontal bar. $\boldsymbol{B}$, Currentvoltage relationships recorded from the cell shown in $\boldsymbol{A}$ collected at the indicated times (1, 2, and 3). C, Mean inward (at $-80 \mathrm{mV}$, black bars, downward) and outward (at $+80 \mathrm{mV}$, gray bars, upward) current from four cells at baseline $\left(25^{\circ} \mathrm{C}\right.$ ), after $\operatorname{cooling}\left(10^{\circ} \mathrm{C}\right)$, and after treatment with $25 \mu \mathrm{M}$ AITC at $25^{\circ} \mathrm{C}$. The $20 \mu \mathrm{m}$ HC-030031 was used to determine TRPA1-specific component of the currents. Data are plotted as mean \pm SEM. D, Fold increase in inward (at $-80 \mathrm{mV}$, black bars, downward) and outward (at $80 \mathrm{mV}$, gray bars, upward) current over baseline at $25^{\circ} \mathrm{C}$ with cooling $\left(10^{\circ} \mathrm{C}\right)$, and after treatment with $25 \mu \mathrm{M} \mathrm{AITC}$ at $25^{\circ} \mathrm{C}$. Data from the same cells as in $C$ are plotted as mean \pm SEM.

the cold. At this time point, there was no tissue injury detectable on visual inspection.

Noxious cold detection. Animals were dosed with either vehicle or HC030031 under blinded conditions (the operator of the cold plate was unaware as to what each animal had received). Sixty minutes after treatment recovery, each animal was carefully placed on a PE34 Cold Plate Analgesia Meter (IITC Life Science) set to $-5^{\circ} \mathrm{C}$ and the built-in timer activated. The number of total responses during the $5 \mathrm{~min}$ observation period was recorded as well as the latency to first response. After each reading, the cold plate was wiped clean of urine and feces and confirmed to be at $-5^{\circ} \mathrm{C}$ before a subsequent animal was tested. On completion of the PWL readings, the animals were killed.

Spared nerve injury-induced cold allodynia. Baseline cold sensitivity was assessed on a $10^{\circ} \mathrm{C}$ cold plate and animals were randomized into vehicle- and drug-treated groups. Spared nerve injury (SNI) surgery was performed as previously described (Decosterd and Woolf, 2000). Briefly, an axotomy and ligation of the tibial and common peroneal nerves was performed, leaving the sural nerve intact. The common peroneal and the tibial nerves were tight-ligated with 5.0 silk and sectioned distal to the ligation, removing 2-4 $\mathrm{mm}$ of the distal nerve stump. Muscle and skin were closed in two layers. Seven days after surgery, paw withdrawal latency was assessed again (pre-Rx). Animals were then subsequently injected intraperitoneally with HC-030031 or vehicle. One hour after compound administration (post-Rx), paw withdrawal latency was again determined.

Methods for mechanical allodynia testing. Mechanical hyperalgesia data were conducted with a Dynamic Plantar Aesthesiometer from Ugo Basile. Mice were acclimated for $60 \mathrm{~min}$ to the testing environment and an average of four exposures per paw were recorded. Baseline von Frey threshold or paw withdrawal latency was measured first and again at 15 min after injection of $4 \mathrm{HNE}$ (as above).

Statistics. For all experiments, asterisks indicate the following: ${ }^{\star} p<$ $0.05,{ }^{* *} p<0.01$, and ${ }^{* * *} p<0.001$.

\section{Results}

Noxious cold activates heterologously expressed TRPA1 channels

In an effort to understand the effect of temperature on TRPA1 gating, we first attempted to recapitulate previous findings showing that noxious cold activates TRPA1 (Story et al., 2003; Sawada et al., 2007; Wang et al., 2008; Karashima et al., 2009). We used whole-cell patch-clamp recordings from HEK cells stably transfected with rat TRPA1. Since $\mathrm{Ca}^{2+}$ permeating through the channel exerts complicated effects, both activating the current and accelerating its rundown (Doerner et al., 2007; Zurborg et al., 2007), these heterologous expression experiments were conducted in the absence of external $\mathrm{Ca}^{2+}$. To eliminate the possibility of nonspecific effects caused by prolonged exposure to low temperatures, we used a perfusion system permitting rapid temperature changes, with a lag time of $<15$ s to completion of a temperature switch (see supplemental Fig. 1, available at www.jneurosci.org as supplemental material). At $25^{\circ} \mathrm{C}$, small outwardly rectifying TRPA 1 currents were observed during voltage ramps from -100 to $100 \mathrm{mV}$ (Fig. $1 A, B)$. Reducing the temperature from 25 to $10^{\circ} \mathrm{C}$ resulted in a clear potentiation of both the inward and outward currents. Once the temperature was increased back to $25^{\circ} \mathrm{C}$, the current rapidly returned to precooling levels. Importantly, the TRPA1-specific blocker HC-030031 virtually abolished the cold-induced current, strongly indicating that the currents were TRPA1 mediated.

To rule out the possibility that residual intracellular calcium contributes to the activation of TRPA1 by cooling, we examined TRPA1 currents in the absence of intracellular calcium. To accomplish this, we released internal calcium stores with inositol 1,4,5-trisphosphate and chelated any remaining free calcium with BAPTA. Under these conditions, cooling still activated TRPA1 currents (data not shown). These results demonstrate that the cold-mediated activation of TRPA1 current is $\mathrm{Ca}^{2+}$ independent, as previously reported (Sawada et al., 2007; Karashima et al., 2009).

We next compared the cold-induced current increase with that generated, within the same cells, by addition of a subsaturating concentration of the agonist AITC (Fig. 1C). Lowering the temperature to $10^{\circ} \mathrm{C}$ increased the basal inward current $\sim 10$ fold, to $\sim 100 \mathrm{pA}$. In contrast, addition of AITC increased the basal current $\sim 300$-fold, resulting in nearly $3000 \mathrm{pA}$ of inward current. In summary, although noxious cold clearly activates TRPA1, the amplitude of TRPA1 current activated by AITC is much larger (Fig. 1D).

\section{Effect of temperature changes on agonist-evoked TRPA1 currents}

Although the TRPA1 currents evoked by noxious cold alone are small, it is possible that noxious cold in combination with other activators of the channel could have a more substantial effect. We therefore studied the impact of cold on TRPA1 currents already 
A
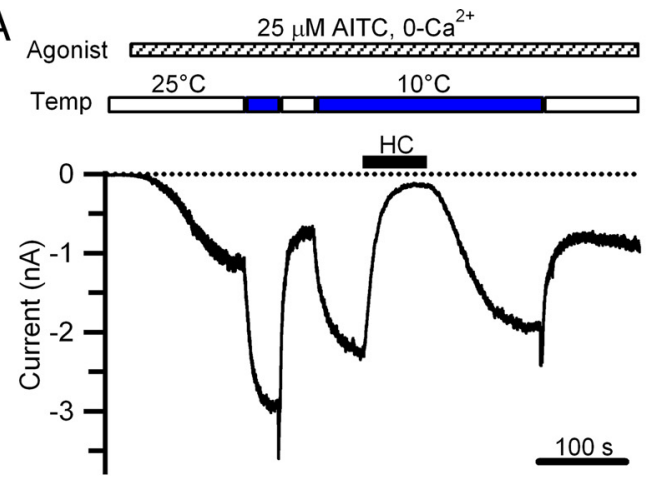

B

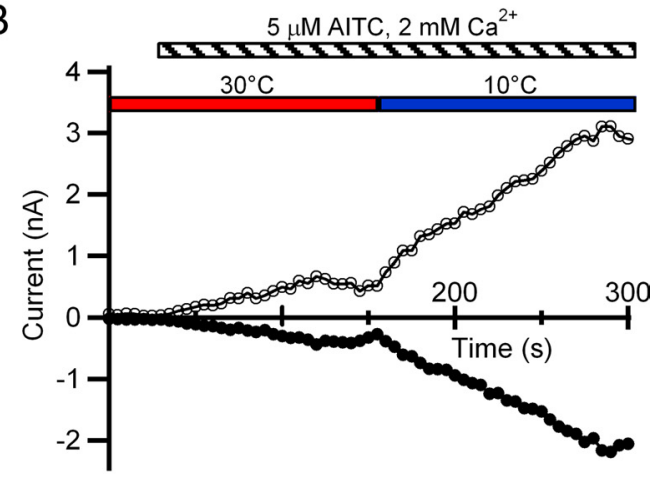

C

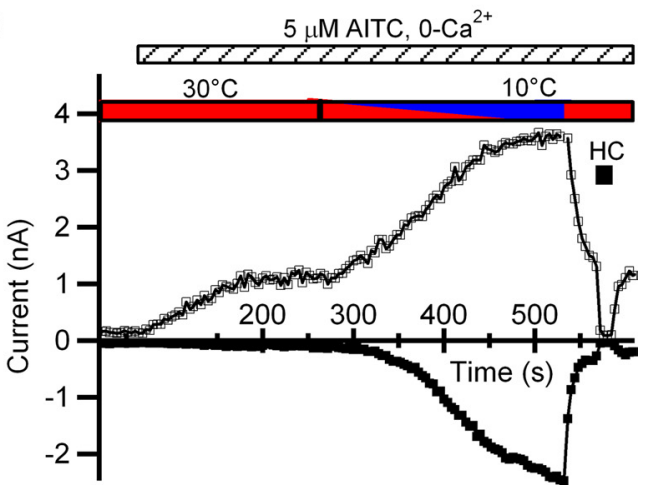

Figure 2. Rapid cooling potentiates TRPA1 currents after activation by agonist. $A$, Continuous whole-cell recordings at $-60 \mathrm{mV}$ from a representative HEK-293 cell expressing rTRPA1. $\mathrm{Ca}^{2+}$-free bath solutions were perfused at either $25^{\circ} \mathrm{C}$ (open horizontal bars) or at $10^{\circ} \mathrm{C}$ (blue horizontal bars). AITC was added during the time indicated by the horizontal bar. The TRPA1specific blocker HC-030031 was added at a concentration of $20 \mu \mathrm{m}$ (black bar; $\mathrm{HC}$ ). The dotted line represents the 0 current level. Decreasing the temperature from 25 to $10^{\circ} \mathrm{C}$ potentiated the current 2.33-fold ( $\pm 0.28 ; n=4)$. $\boldsymbol{B}$, Whole-cell recording from a representative HEK-293 cell expressing rTRPA1. From a holding potential of $0 \mathrm{mV}, 400 \mathrm{~ms}$ ramps from -100 to $100 \mathrm{mV}$ applied every $4 \mathrm{~s}$ were used to elicit inward (measured at $-80 \mathrm{mV}$, filled circles) and outward (measured at $80 \mathrm{mV}$, open circles) currents, which are plotted as a function of time. The bath solution contained $2 \mathrm{~mm} \mathrm{Ca}^{2+}$. As in $A$, a rapid temperature exchange was achieved using two different temperature control and perfusion systems preset at the indicated temperatures $\left(30^{\circ} \mathrm{C}\right.$, red horizontal bars, or $10^{\circ} \mathrm{C}$, blue horizontal bars) to ensure a rapid transition from 30 to $10^{\circ} \mathrm{C}$ within $15 \mathrm{~s}$. C, Same as in $\boldsymbol{B}$ but without $\mathrm{Ca}^{2+}$ in the bath solution. Here, temperature is reduced from 30 to $10^{\circ} \mathrm{C}$ at a very slow rate $\left(\sim 20^{\circ} \mathrm{C} / 5 \mathrm{~min}\right)$. Under these conditions, lowering the temperature resulted in clear current potentiation.

activated by the addition of agonists. TRPA1 currents activated by $25 \mu \mathrm{M}$ AITC at $25^{\circ} \mathrm{C}$ were strongly potentiated when the temperature was lowered to $10^{\circ} \mathrm{C}$ (Fig. $2 \mathrm{~A}$ ). This potentiation was reversible, and completely blocked by HC-030031, indicating that it was TRPA1 mediated.

To determine whether the strong, cooling-induced potentiation of TRPA1 was limited to AITC-induced currents, we tested two other agonists of TRPA1. Currents activated by acrolein, a potent pulmonary irritant, were also strongly potentiated by cold (supplemental Fig. $2 \mathrm{~A}$, available at www.jneurosci.org as supplemental material). We also examined 4-HNE, a putative endogenous activator of TRPA1. Unlike AITC, 4-HNE irreversibly activated TRPA1. Thus, after removal of 4-HNE, the level of current remained stable for a prolonged period of time. Cooling from 25 to $10^{\circ} \mathrm{C}$ substantially potentiated these persistent currents (supplemental Fig. $2 B$, available at www.jneurosci.org as supplemental material).

The cold-induced potentiation of TRPA1 currents in the presence of agonists conflicts with a previous report showing that AITC-activated TRPA1 currents decrease when the temperature is lowered from 30 to $10^{\circ} \mathrm{C}$ (Karashima et al., 2009). Karashima et al. demonstrated that, in the presence of $5 \mu \mathrm{M}$ AITC, slowly cooling cells heterologously expressing TRPA 1 from 30 to $10^{\circ} \mathrm{C}$ resulted in decreased currents. They noted that, although the overall current amplitude decreased in this paradigm, the open probability of TRPA1 was increased by cooling. When we repeated the Karashima protocol by adding $\mathrm{Ca}^{2+}$ to the external solution and slowly cooling the cells from 30 to $10^{\circ} \mathrm{C}$ over the course of $5 \mathrm{~min}$, we saw results very similar to those previously reported (supplemental Fig. 3, available at www.jneurosci.org as supplemental material). We hypothesize that the discrepancy in the effect of cooling observed in these two protocols is attributable to significant calcium-induced desensitization of TRPA1 observed with the very slow rate of cooling. Indeed, cold-induced potentiation of TRPA1 current was also observed in the presence of extracellular $\mathrm{Ca}^{2+}$ when the temperature was rapidly decreased $\left(>10^{\circ} \mathrm{C}\right.$ in $3 \mathrm{~s}$ ) (Fig. $2 \mathrm{~B}$ ). We found that cold also augmented TRPA1 currents with the slower rate of cooling $\left(\sim 4^{\circ} \mathrm{C} /\right.$ min) used by Karashima et al. when extracellular calcium was absent (Fig. 2C).

Although cooling cells from 30 or $25^{\circ} \mathrm{C}$ down to $10^{\circ} \mathrm{C}$ clearly potentiated agonist-activated currents, we wondered whether potentiation of agonist-activated TRPA1 currents could be achieved by lowering the temperature within a more physiologically relevant range. Figure $3 \mathrm{~A}$ demonstrates that cooling from 30 to $20^{\circ} \mathrm{C}$ in the presence of $5 \mu \mathrm{M}$ AITC potentiated TRPA 1 currents by approximately fourfold. Even when the AITC concentration was increased to $50 \mu \mathrm{M}$, this mild cooling enhanced the TRPA1 current by more than twofold (Fig. 3B). In contrast, at $500 \mu \mathrm{M}$ AITC (a near-saturating concentration), cooling resulted in a small current decrease (Fig. $3 C$ ), suggesting that the magnitude of cold potentiation decreases as higher levels of TRPA1 activation are achieved.

That mild cooling potentiates TRPA1 in the presence of agonists was also observed under more physiological recording conditions. We performed recordings starting at $35^{\circ} \mathrm{C}$ in the presence of $2 \mathrm{mM}$ external $\mathrm{Ca}^{2+}$. In these conditions, cooling to $20^{\circ} \mathrm{C}$ in the presence of subsaturating concentrations of AITC also led to a clear increase in current (supplemental Fig. $4 A, B$, available at www.jneurosci.org as supplemental material). Overall, these results demonstrate that physiologically relevant fast cooling potentiates TRPA1 in the presence of an agonist.

\section{Effect of cold on agonist-evoked native TRPA1 currents in rat} DRG neurons

To examine whether cooling elicited similar effects on native TRPA1 currents, we tested the effect of cooling on acutely isolated adult rat DRG neurons. To more accurately simulate the normal physiological environment, $2 \mathrm{mM} \mathrm{Ca}^{2+}$ was included in the extracellular buffer in all these experiments. In multiple 


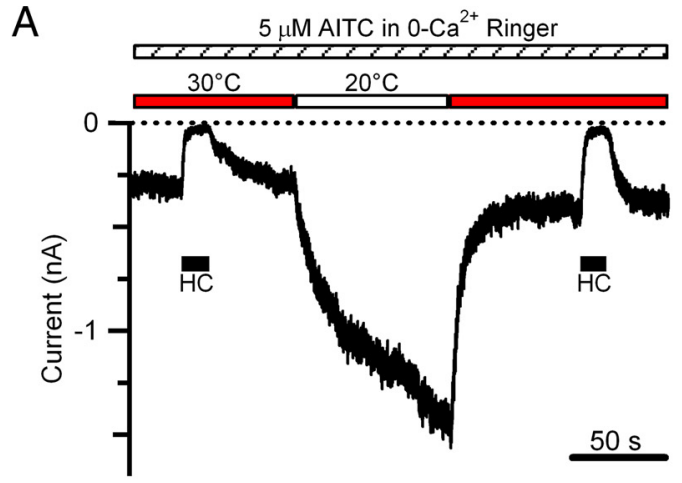

B

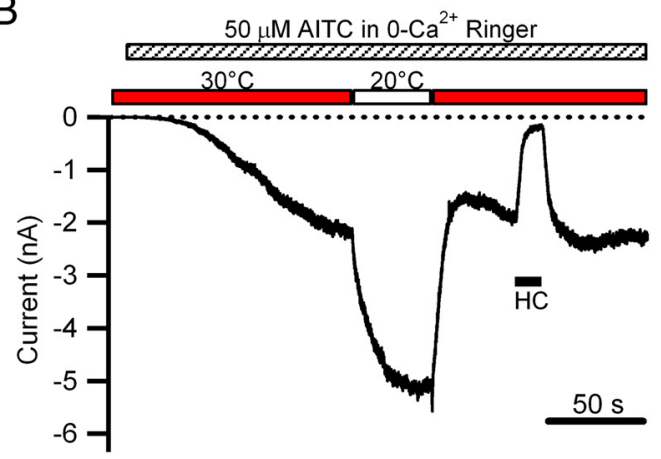

C

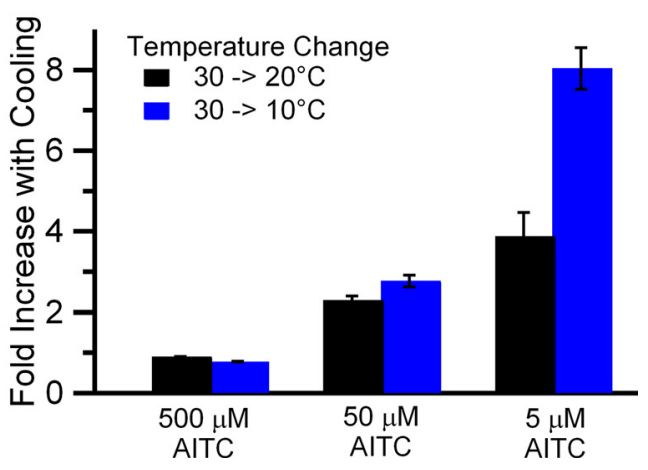

Figure 3. Magnitude of cooling-induced TRPA1 potentiation is dependent on the temperature and AITC concentration. $A, B$, Representative continuous whole-cell recordings at $-60 \mathrm{mV}$ from HEK-293 cells expressing rTRPA1 and perfused with $\mathrm{Ca}^{2+}$-free bath solutions containing AlTC at $5 \mu \mathrm{M}(\boldsymbol{A})$ or $50 \mu \mathrm{M}(\boldsymbol{B})$. AlTC was perfused at $30^{\circ} \mathrm{C}$ (red horizontal bars) or $20^{\circ} \mathrm{C}$ (open horizontal bars). Addition of $5 \mu \mathrm{m}$ AITC caused a very slow activation of the current. For this reason, the early phase of current development is omitted in $A$. The $20 \mu \mathrm{M} \mathrm{HC}-030031$ was perfused at the times indicated by the black horizontal bars. C, Quantification of the increase in inward current evoked by cooling over that evoked by AITC alone. Cooling from 30 to $20^{\circ} \mathrm{C}$ (black bars) or from 30 to $10^{\circ} \mathrm{C}$ (blue bars) is shown in the presence of varying concentrations of AITC. The bars show mean \pm SEM of three (500 $\mu$ M AITC) or four (50 and $5 \mu \mathrm{M}$ AITC) cells from whole-cell recordings as shown in $\boldsymbol{A}$ and $\boldsymbol{B}$.

TRPA1-expressing neurons, currents activated by perfusion with either AITC (Fig. 4A) or 4-HNE (Fig. $4 B$ ) were reversibly potentiated threefold by cooling from 25 to $10^{\circ} \mathrm{C}$. Cold-potentiated currents were blocked by HC-030031, demonstrating that they were mediated by TRPA1. The cooling-induced current increase in the presence of agonists is quantified in Figure $4 C$. Note that, in the absence of a chemical agonist, temperature reduction did not significantly alter baseline current (Fig. $4 A, B$ ), indicating that the effect of cold on native TRPA1 is likely minimal in the absence of an agonist. However, cooling dramatically potentiates agonistevoked TRPA1 currents in DRG neurons as it did after heterologous expression.
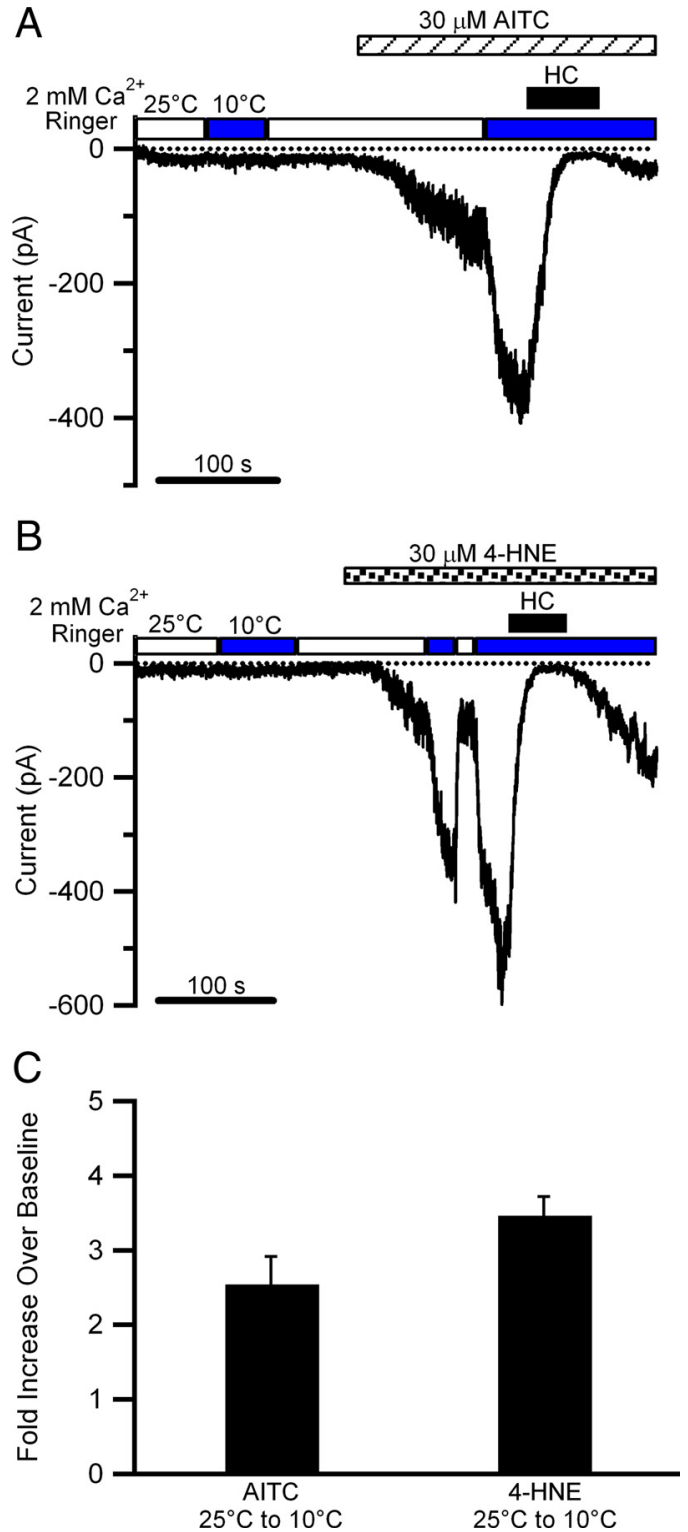

Figure 4. Cooling potentiates AITC- or 4-HNE-activated currents in isolated DRG neurons. $A, B$, Continuous whole-cell recordings at $-60 \mathrm{mV}$ from isolated rat DRG neurons. The temperature of the perfusion solutions was switched from $25^{\circ} \mathrm{C}$ (open horizontal bars) to $10^{\circ} \mathrm{C}$ (blue horizontal bars) both in absence of an agonist and in the presence of AITC $(\boldsymbol{A})$ or 4-HNE $(\boldsymbol{B})$. The currents activated by those two agonists were blocked by $20 \mu \mathrm{M} \mathrm{HC}-030031$ (black horizontal bars). C, Quantification of the fold increase in inward current evoked by cooling from 25 to $10^{\circ} \mathrm{C}$ in the presence of AITC $(30 \mu \mathrm{M})$ or 4-HNE $(30 \mu \mathrm{M})$. The bars represent the mean \pm SEM of four (AITC) or five (4-HNE) DRG neurons.

\section{In vivo effects of 4-HNE on cold hypersensitivity}

Since 4-HNE sensitized native TRPA 1 currents to cold in vitro, we explored whether the same effects could be observed in vivo at the behavioral level. Cold-induced pain is often measured by monitoring nocifensive behaviors such as jumping or licking/flicking of the hindpaw after placement on a cold plate. Reports on the acute cold sensitivity differences between WT and TRPA1-null mice have been inconsistent (Bautista et al., 2006; Kwan et al., 2006; Karashima et al., 2009), perhaps because of procedural differences. We chose to examine the effect of 4-HNE on coldelicited behavior using a $0^{\circ} \mathrm{C}$ cold plate to avoid confounding effects of cold sensing with tissue damage, which may occur at lower temperatures. 

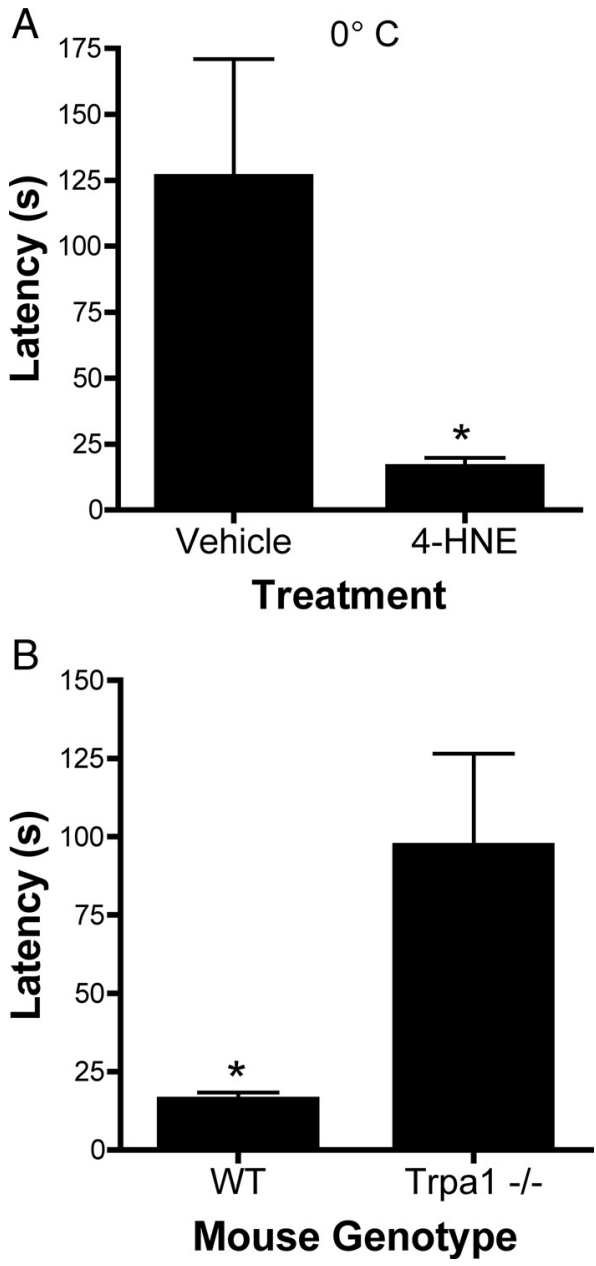

Figure 5. Five millimolar 4-HNE induces TRPA1-dependent cold allodynia. $A, B$, Mice were injected with $5 \mathrm{~mm} 4-\mathrm{HNE}$ or vehicle and then placed on a $0^{\circ} \mathrm{C}$ cold plate and observed for latency to first pain response. $A$, Cold responses from vehicle-treated and $5 \mathrm{~mm} 4$-HNE-treated mice are compared. $\boldsymbol{B}$, Cold responses from $5 \mathrm{~mm} 4$-HNE-treated WT and Trpa1 - / - mice are compared. The bars represent the mean \pm SEM (** $p<0.01)$.

In contrast to previous reports (Trevisani et al., 2007), we found intraplantar injection of $5 \mathrm{~mm} 4$-HNE was insufficient to elicit pain behavior at room temperature (data not shown). We examined whether this concentration of 4-HNE induced cold hypersensitivity. Indeed, injection of 4-HNE dramatically reduced the onset of nocifensive behaviors in response to a $0^{\circ} \mathrm{C}$ cold plate $(16 \pm 3.4$ vs $126 \pm 44 \mathrm{~s} ; p<0.05)$ (Fig. $5 A)$. The 4 -HNEinduced cold sensitivity depended on TRPA1, as the effects were greatly diminished in TRPA1-deficient mice compared with wild-type littermates $(p<0.05)$ (Fig. $5 B)$. In the absence of 4 -HNE injection, no significant difference in onset of coldevoked behavior was observed between wild-type mice and TRPA1-deficient littermates (supplemental Fig. 5, available at www.jneurosci.org as supplemental material). This demonstrates the prominent role of TRPA1 in cold nociception in the presence of TRPA1 agonists, and agrees well with our electrophysiological findings.

Injection of $5 \mathrm{~mm}$ 4-HNE also induced heat hyperalgesia and mechanical allodynia as detected by the Hargreave's plantar radiant heat test and assessment with von Frey filaments (supplemental Fig. 6, available at www.jneurosci.org as supplemental material). This increased sensitivity to heat and mechanical stimuli was observed in both $\operatorname{Trpa1}^{-/-}$and $\operatorname{Trpa1} 1^{+/+}$mice, indicat- ing that, although 4-HNE-induced cold allodynia is dependent on functional TRPA1, the heat hyperalgesia and mechanical allodynia are not. Therefore, at least at these concentrations, 4-HNE can also affect nociceptive behavior through TRPA1-independent mechanisms. These results differ from previous reports suggesting that the mechanical allodynia caused by 4-HNE depends on expression of functional TRPA1 (Trevisani et al., 2007). Experimental differences may contribute to this apparent conflict. First, the concentration of 4 -HNE used in our study $(50 \mathrm{nmol})$ is much lower than that used by Trevisani et al. (150 nmol). Second, we used a genetic disruption of TRPA1 to study its function, whereas the previous results depend on gentamycin and camphor, which are weak and poorly selective inhibitors of TRPA1.

\section{Cold hypersensitivity in pathological conditions}

Since endogenous TRPA1 agonists such as reactive prostaglandins, reactive oxygen species, and 4 -HNE are produced during inflammatory responses, we investigated the role of TRPA1 in cold responses during the localized inflammation elicited by injection of CFA into the hindpaw in the rat. We measured paw withdrawal latency on exposure to a $5^{\circ} \mathrm{C}$ cold plate at baseline, after CFA injection, and after treatment with HC-030031 or vehicle. Forty-eight hours after intraplantar injection with CFA, the paw withdrawal latency had decreased compared with withdrawal latencies at baseline (Fig. $6 A, 89.7 \pm 16.6$ s goes to $33.7 \pm$ $9.9 \mathrm{~s}$ ) similar to that previously reported (Allchorne et al., 2005). Treatment with HC-030031 (150 mg/kg, i.p.) increased the paw withdrawal latency from $36.3 \pm 2.8$ to $58.9 \pm 5.3 \mathrm{~s}(n=7)$ (Fig. $6 B)$. Similar results have been demonstrated with locally injected AP-18, another TRPA1 antagonist (Petrus et al., 2007). Vehicle treatment had no effect on the cold-evoked paw withdrawal latency (Fig. 6A). The observed increase in paw withdrawal latency with HC-030031 in CFA-treated animals likely represents a specific effect on the cold allodynia, since the paw withdrawal latency of the uninflamed (contralateral) paw remained unaffected $(87.8 \pm 3.8 \mathrm{~s}$ after treatment with HC-030031 compared with $84.8 \pm 1.8 \mathrm{~s}$ ) (supplemental Fig. 7, available at www.jneurosci.org as supplemental material). Furthermore, animals treated with HC-030031 at this dose did not show any impairment in an accelerating rotarod assay (McNamara et al., 2007). The selectivity profile of HC-030031 (McNamara et al., 2007; Eid et al., 2008) further supports the observation that the observed analgesic effects are mediated through TRPA1.

Since we saw no effect of HC-030031 on the withdrawal latency of the uninjured paw to $5^{\circ} \mathrm{C}$, we asked whether colder temperatures would unmask a potential role for TRPA1 in the detection of environmental cold. In naive rats, we injected $\mathrm{HC}$ 030031 ( $150 \mathrm{mg} / \mathrm{kg}$, i.p.) $1 \mathrm{~h}$ before determining paw withdrawal latency on a cold plate held at $-5^{\circ} \mathrm{C}$. Despite achieving similar plasma exposure as in the previous study $(8 \pm 1 \mu \mathrm{g} / \mathrm{ml})$, HC030031 did not alter the paw withdrawal latency compared with vehicle-treated animals and had no effect on the number of elicited pain behaviors observed over $5 \mathrm{~min}$ (Fig. 7A) $(n=16)$ (Fig. $7 B$ ) (average plasma level of $7 \pm 4 \mu \mathrm{g} / \mathrm{ml} ; n=8$ ).

Finally, we investigated whether TRPA1 is involved in the cold hypersensitivity that comprises a prominent part of the neuropathic pain phenotype in the spared nerve injury model. At the preinjury baseline, vehicle-treated and HC-030031-treated rats showed similar paw withdrawal latencies when placed on a $10^{\circ} \mathrm{C}$ cold plate $(137.6 \pm 6.2$ compared with $148.3 \pm 1.7 \mathrm{~s})($ Fig. $8 B, C)$. To induce nerve injury, we ligated the tibial and common peroneal nerve, resulting in greatly reduced paw withdrawal latencies after 7 d similar to previous reports (Allchorne et al., 2005). 

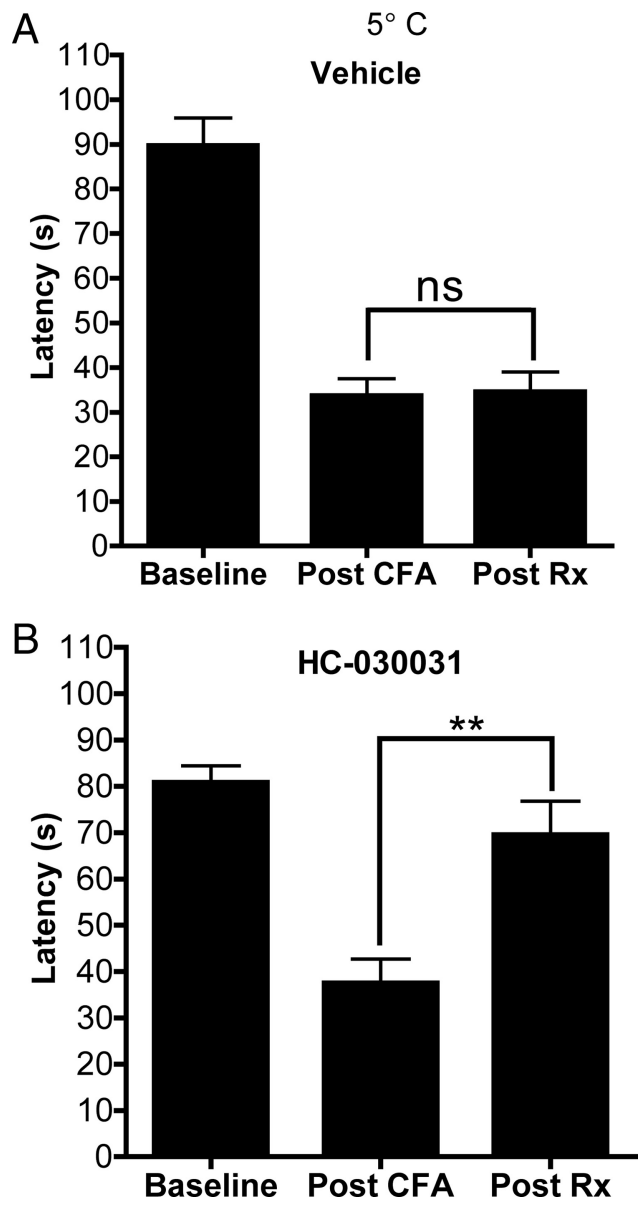

Figure 6. HC-030031 ameliorates CFA-induced cold allodynia. $\boldsymbol{A}, \boldsymbol{B}$, The latency to first pain response on a $5^{\circ} \mathrm{C}$ cold plate was measured in rats before injection of CFA into one hindpaw (baseline), $48 \mathrm{~h}$ after injection of (FA (post-CFA), and again after treatment with either HC030031 or vehicle (post-Rx). Paws injected with CFA are evaluated at baseline, post-CFA, and post-RX with vehicle $(\boldsymbol{A})$ and $\mathrm{HC}-030031(\boldsymbol{B})$. The bars represent the mean $\pm \mathrm{SEM}(n=7)$ $\left({ }^{* *} p<0.01\right)$.

Treatment with HC-030031 significantly increased paw withdrawal latency, to $96.8 \pm 12.1 \mathrm{~s}(150 \mathrm{mg} / \mathrm{kg}$, i.p.; two-way ANOVA, $p<0.001$ ) (Fig. 8A,C), whereas there was no significant change in the paw withdrawal latency of animals treated with the vehicle $(63.7 \pm 13.1 \mathrm{~s})$ (Fig. $8 \mathrm{~A}, \mathrm{~B})$. Plasma levels of HC030031 at the time of killing were similar to those seen in previous experiments $(11 \pm 1 \mu \mathrm{g} / \mathrm{ml})$. We conclude that TRPA1 is a significant contributor to cold allodynia in both neuropathic and inflammatory pain states.

\section{Discussion}

TRPA1 was initially proposed to be a noxious cold receptor (Story et al., 2003), a hypothesis that was later contested (Jordt et al., 2004; Sawada et al., 2007; Zurborg et al., 2007). Since then, the role of TRPA1 in the detection of noxious cold has remained uncertain because genetic deletion of TRPA1 failed to resolve the controversy (Kwan et al., 2006; Bautista et al., 2007; Fajardo et al., 2008; Karashima et al., 2009; Madrid et al., 2009; Knowlton et al., 2010). Our results provide new evidence that supports a prominent role for TRPA1 in cold hypersensitivity rather than cold detection. Once TRPA 1 has been activated by an agonist, we find both in vitro and in vivo that TRPA1 plays a substantial role in driving cold allodynia.
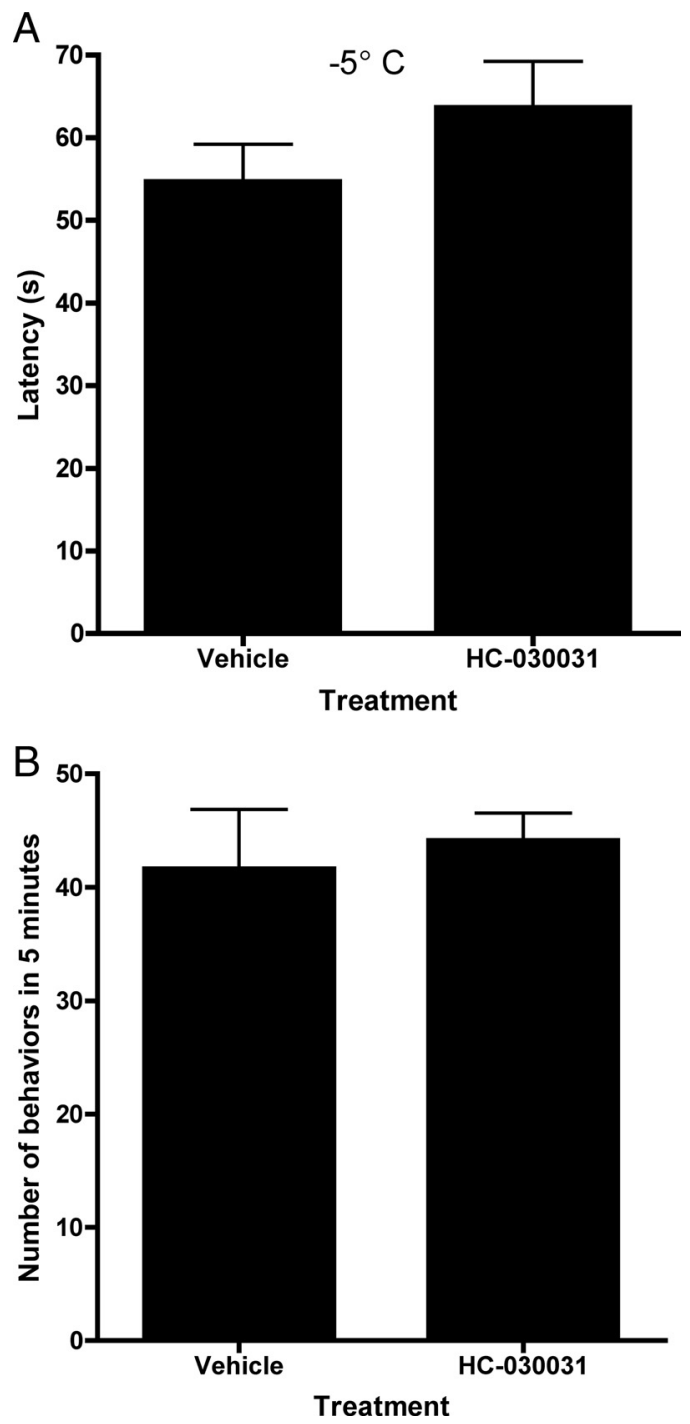

Figure 7. HC-030031 has no effect on the detection of noxious cold in the absence of CFA injection. Rats injected with either $\mathrm{HC}-030031$ or vehicle were placed on a $-5^{\circ} \mathrm{C}$ cold plate. $\boldsymbol{A}$, Latency to first response was measured in vehicle- or HC-030031-treated animals. The bars represent the mean \pm SEM $(n=16)$. $\boldsymbol{B}$, Number of pain behaviors exhibited in 5 min was measured in vehicle- or HC-030031-treated animals. The bars represent the mean $\pm \operatorname{SEM}(n=8)$.

\section{Effect of cold on TRPA1 current activation}

Our results demonstrate that cold can activate TRPA1 in a heterologous expression system, but the current amplitude activated by cold alone is $1 / 30$ th of that activated by a submaximal concentration of AITC, the reactive chemical that underlies the pungency of mustard. Cooling in combination with exposure to AITC produces a much more substantial increase in TRPA1 current amplitude. This cooling-elicited current potentiation also occurs after activation by a presumed endogenous activator 4-HNE or the pulmonary irritant acrolein. Cooling-induced current potentiation occurred across TRPA1 clones from different species (rat, mouse, human) (D. del Camino, unpublished data) and across a variety of recording conditions, in the presence or absence of extracellular $\mathrm{Ca}^{2+}$. Native TRPA1 currents in acutely isolated adult DRG neurons also showed marked sensitivity to cooling after stimulation with an agonist, and behavioral experiments with 4-HNE and cold are in agreement with our electrophysiological data. 
A

$10^{\circ} \mathrm{C}$

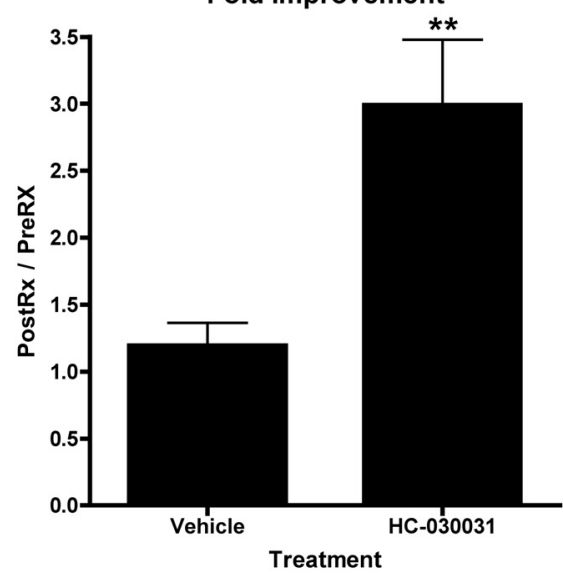

B

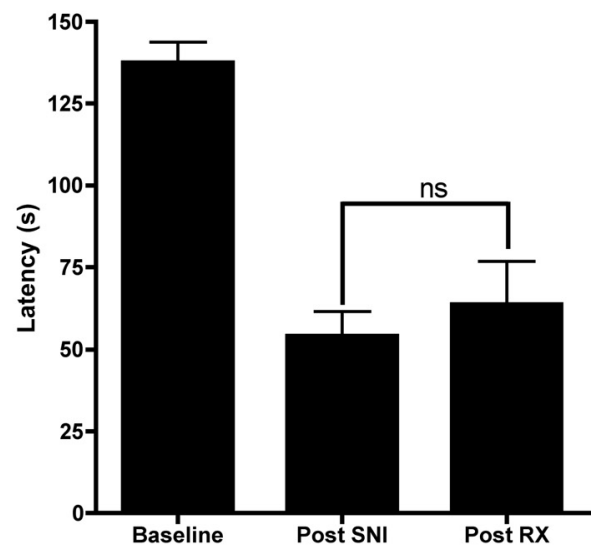

Measurement

C

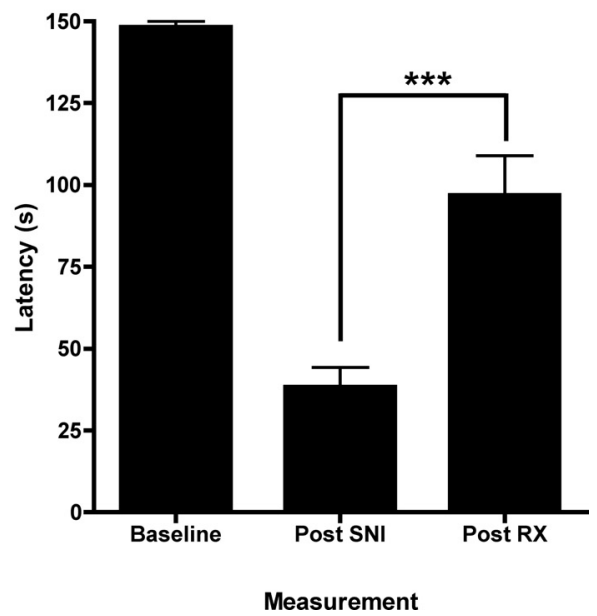

Figure 8. Nerve injury in rats induces cold allodynia that is ameliorated by blocking TRPA1. $A$, The latency to first reaction to placement on a $10^{\circ} \mathrm{C}$ cold plate was determined in rats $7 \mathrm{~d}$ after SNI surgery $(n=10)$. The response latency was then measured after treatment with either vehicle or $\mathrm{HC}-030031$ and is presented as a ratio of posttreatment to pretreatment response latency $\left.{ }^{* *} p<0.01\right) . B, C$, Response latency of rats after placement on a $10^{\circ} \mathrm{C}$ cold plate before $S \mathrm{NI}, 7 \mathrm{~d}$ after $S \mathrm{NI}$, and $1 \mathrm{~h}$ after treatment with vehicle $(\boldsymbol{B})$ or HC-030031 (C) was measured $\left({ }^{* * *} p<0.001\right)$. The bars represent the mean \pm SEM.
The mechanism of cooling-induced potentiation of TRPA1 current could, in principle, be the result of effects on singlechannel conductance, open probability, the number of TRPA1 channels expressed in the membrane, or a combination of these (Schmidt et al., 2009). It has been shown that, although cooling decreases the single-channel conductance of TRPA1, it increases the open probability of this channel, even in excised inside-out patches (Sawada et al., 2007; Karashima et al., 2009). The simplest mechanism by which cooling might enhance agonist-activated current is by increasing the open probability of the channel, through either direct or indirect effects on channel gating. Ultimately, the interplay between changes in open probability and decrease in single-channel conductance will determine net effect on current. This hypothesis is consistent with our observation that cooling has the greatest effect when agonist concentrations are low; at higher agonist concentrations, the open probability is already so high that any additional increase caused by cooling is insufficient to overcome the associated decrease in singlechannel conductance.

In the absence of external $\mathrm{Ca}^{2+}$, the cold potentiation of agonist-induced TRPA1 currents is very clear regardless of the rate of cooling. In the presence of $\mathrm{Ca}^{2+}$, the situation is more complicated because of the dual effect of $\mathrm{Ca}^{2+}$, which causes both activation and desensitization of the channel. In fact, we found that, although a very slow cooling rate $\left(30-10^{\circ} \mathrm{C}\right.$ in $\left.\sim 5 \mathrm{~min}\right)$ leads to current decrease in the heterologous system, a faster cooling rate $\left(30-10^{\circ} \mathrm{C}\right.$ in $\left.\sim 15 \mathrm{~s}\right)$ causes clear current potentiation. A possible explanation for this result is that, during slow cooling, the combined effect of decreased single-channel conductance and $\mathrm{Ca}^{2+}$-induced desensitization are dominant, inhibiting the current. Conversely, with faster cooling, the combined agonist effects of cold and $\mathrm{Ca}^{2+}$ may be more prominent, causing current potentiation. Regardless of mechanism, we find that even a decrease in temperature in the innocuous range from 30 to $20^{\circ} \mathrm{C}$ potentiates TRPAl currents when low concentrations of AITC are present. Thus, although it is has been suggested that TRPA1 is only activated by noxious cold temperatures (Story et al., 2003), our results indicate even mild cooling can have profound effects on TRPA 1 activation in vitro and in this way could contribute to cold allodynia (pain in response to a normally innocuous level of cooling).

\section{TRPA1 in the detection of environmental cold}

In contrast to TRPV1 (Caterina et al., 2000) and TRPM8 (Bautista et al., 2007; Colburn et al., 2007; Dhaka et al., 2007), which are thermosensors that contribute to thermal preference in the absence of agonist, we observe only a limited role for TRPA1 in normal cold sensation. In our expression system, we saw a small tonic TRPAl current at $25^{\circ} \mathrm{C}$ that was weakly potentiated by cold, whereas in acutely isolated rat AITC-responsive DRG neurons, we found that noxious cold $\left(10^{\circ} \mathrm{C}\right)$ did not elicit a clear response from neurons. These results are very similar to recent findings looking at cold sensation in trigeminal neurons. Madrid et al. (2009) showed that only a very small percentage of AITCresponsive neurons were also cold responsive and that the percentage of cold-sensitive neurons was not decreased by genetic deletion of TRPA1. In vivo, we observed no significant difference in cold sensitivity between WT and Trpa1 ${ }^{-1-}$ mice. This is in agreement with the study by Bautista et al. (2006), even though we used one of the lines generated by Kwan et al. (2006). Similarly, when we turned to a selective antagonist of TRPA1, HC030031, we saw no effects on either the number of pain behaviors or the latency to the first pain behavior of rats placed on a cold 
plate held at $-5^{\circ} \mathrm{C}$. There was also no difference in the latency to pain behaviors at $5^{\circ} \mathrm{C}$. These data suggest that acute TRPA1 inhibition does not affect cold sensation in naive animals. Although Karashima et al. (2009) also failed to detect a difference in time to onset of pain behaviors on the cold plate, they did see a difference in the number of times the WT mice responded compared with Trpa1 ${ }^{-1-}$ animals. More recently, Bevan and colleagues developed a novel cold-plate assay that measures paw withdrawal latencies of lightly restrained mice, making sure that there is full contact between the paws and the plate (Gentry et al., 2010). Using this method, they observe robust deficits in cold nociception in both TRPM8- and TRPA1-deficient mice. The discrepancy between the various cold nociception data sets is likely attributable to differences in methodologies and assay sensitivity. Finally, although our results indicate that TRPA1 may not contribute substantially to the detection of noxious cold in the DRG neurons, as also shown in trigeminal neurons (Madrid et al., 2009), a recent report suggests that TRPA1 mediates the detection of cold in nodose sensory neurons (Fajardo et al., 2008). Thus, it is possible that the function of TRPA1 differs in different neurons, perhaps as a result of subcellular milieu.

\section{TRPA1 contributes to cold allodynia under pathological conditions}

Although we observed no difference in normal cold sensation between WT and Trpa1 ${ }^{-1-}$ animals, injection of the TRPA1 agonist 4-HNE led to a profound TRPA1-dependent cold hypersensitivity. These data agree with our findings in adult rat DRG neurons: 4-HNE-activated currents were strongly potentiated by lowering the temperature. To determine the role of TRPA1 in cold hypersensitivity in pathological pain states, we studied cold responses during acute local inflammation induced by intraplantar injection of CFA or after nerve injury induced by surgical ligation. In both of these paradigms, treating rats with the specific TRPA1 antagonist HC-030031 yielded similar results, significantly decreasing cold allodynia. In agreement with our results, recent reports indicate that CFA-induced cold hypersensitivity to tetrafluoroethane is also greatly reduced by treatment with HC030031 (da Costa et al., 2010).

In contrast to previous reports that the role of TRPA1 in pathological pain conditions was attributable to an increase in expression levels (Obata et al., 2005; Ji et al., 2008), we see no increase in TRPA1 transcript in the ipsilateral DRG after either SNI or CFA injection (L. B. Barrett and C. J. Woolf, unpublished data). Although this work does not directly address which TRPA1 activator or activators lead to the sensitization in these models of peripheral inflammatory and neuropathic pain, we posit that endogenous TRPA1 agonists present in pathological pain states potentiate the effects of cold. Together, our in vitro and in vivo results suggest that blocking TRPA1 activity could reverse cold allodynia in pathological conditions.

\section{References}

Allchorne AJ, Broom DC, Woolf CJ (2005) Detection of cold pain, cold allodynia and cold hyperalgesia in freely behaving rats. Mol Pain 1:36.

Andersson DA, Gentry C, Moss S, Bevan S (2008) Transient receptor potential A1 is a sensory receptor for multiple products of oxidative stress. J Neurosci 28:2485-2494.

Bang S, Hwang SW (2009) Polymodal ligand sensitivity of TRPAl and its modes of interactions. J Gen Physiol 133:257-262.

Bautista DM, Jordt SE, Nikai T, Tsuruda PR, Read AJ, Poblete J, Yamoah EN, Basbaum AI, Julius D (2006) TRPA1 mediates the inflammatory actions of environmental irritants and proalgesic agents. Cell 124:1269-1282.

Bautista DM, Siemens J, Glazer JM, Tsuruda PR, Basbaum AI, Stucky CL,
Jordt SE, Julius D (2007) The menthol receptor TRPM8 is the principal detector of environmental cold. Nature 448:204-208.

Bessac BF, Sivula M, von Hehn CA, Escalera J, Cohn L, Jordt SE (2008) TRPA1 is a major oxidant sensor in murine airway sensory neurons. J Clin Invest 118:1899-1910.

Caterina MJ, Leffler A, Malmberg AB, Martin WJ, Trafton J, Petersen-Zeitz KR, Koltzenburg M, Basbaum AI, Julius D (2000) Impaired nociception and pain sensation in mice lacking the capsaicin receptor. Science 288:306-313.

Colburn RW, Lubin ML, Stone DJ Jr, Wang Y, Lawrence D, D’Andrea MR, Brandt MR, Liu Y, Flores CM, Qin N (2007) Attenuated cold sensitivity in TRPM8 null mice. Neuron 54:379-386.

Cruz-Orengo L, Dhaka A, Heuermann RJ, Young TJ, Montana MC, Cavanaugh EJ, Kim D, Story GM (2008) Cutaneous nociception evoked by 15-delta PGJ2 via activation of ion channel TRPA1. Mol Pain 4:30.

da Costa DS, Meotti FC, Andrade EL, Leal PC, Motta EM, Calixto JB (2010) The involvement of the transient receptor potential Al (TRPA1) in the maintenance of mechanical and cold hyperalgesia in persistent inflammation. Pain 148:431-437.

Decosterd I, Woolf CJ (2000) Spared nerve injury: an animal model of persistent peripheral neuropathic pain. Pain 87:149-158.

Dhaka A, Murray AN, Mathur J, Earley TJ, Petrus MJ, Patapoutian A (2007) TRPM8 is required for cold sensation in mice. Neuron 54:371-378.

Doerner JF, Gisselmann G, Hatt H, Wetzel CH (2007) Transient receptor potential channel $\mathrm{Al}$ is directly gated by calcium ions. J Biol Chem 282:13180-13189.

Eid SR, Crown ED, Moore EL, Liang HA, Choong KC, Dima S, Henze DA, Kane SA, Urban MO (2008) HC-030031, a TRPA1 selective antagonist, attenuates inflammatory- and neuropathy-induced mechanical hypersensitivity. Mol Pain 4:48.

Fajardo O, Meseguer V, Belmonte C, Viana F (2008) TRPA1 channels mediate cold temperature sensing in mammalian vagal sensory neurons: pharmacological and genetic evidence. J Neurosci 28:7863-7875.

Gentry C, Stoakley N, Andersson DA, Bevan S (2010) The roles of iPLA2, TRPM8 and TRPA1 in chemically induced cold hypersensitivity. Mol Pain 6:4.

Hinman A, Chuang HH, Bautista DM, Julius D (2006) TRP channel activation by reversible covalent modification. Proc Natl Acad Sci U S A 103:19564-19568.

Jaquemar D, Schenker T, Trueb B (1999) An ankyrin-like protein with transmembrane domains is specifically lost after oncogenic transformation of human fibroblasts. J Biol Chem 274:7325-7333.

Ji G, Zhou S, Carlton SM (2008) Intact Adelta-fibers up-regulate transient receptor potential A1 and contribute to cold hypersensitivity in neuropathic rats. Neuroscience 154:1054-1066.

Jordt SE, Bautista DM, Chuang HH, McKemy DD, Zygmunt PM, Högestätt ED, Meng ID, Julius D (2004) Mustard oils and cannabinoids excite sensory nerve fibres through the TRP channel ANKTM1. Nature 427:260-265.

Karashima Y, Talavera K, Everaerts W, Janssens A, Kwan KY, Vennekens R, Nilius B, Voets T (2009) TRPA1 acts as a cold sensor in vitro and in vivo. Proc Natl Acad Sci U S A 106:1273-1278.

Knowlton WM, Bifolck-Fisher A, Bautista DM, McKemy DD (2010) TRPM8, but not TRPA1, is required for neural and behavioral responses to acute noxious cold temperatures and cold-mimetics in vivo. Pain 150:340-350.

Kwan KY, Corey DP (2009) Burning cold: involvement of TRPA1 in noxious cold sensation. J Gen Physiol 133:251-256.

Kwan KY, Allchorne AJ, Vollrath MA, Christensen AP, Zhang DS, Woolf CJ, Corey DP (2006) TRPAl contributes to cold, mechanical, and chemical nociception but is not essential for hair-cell transduction. Neuron 50:277-289.

Macpherson LJ, Dubin AE, Evans MJ, Marr F, Schultz PG, Cravatt BF, Patapoutian A (2007a) Noxious compounds activate TRPA1 ion channels through covalent modification of cysteines. Nature 445:541-545.

Macpherson LJ, Xiao B, Kwan KY, Petrus MJ, Dubin AE, Hwang S, Cravatt B, Corey DP, Patapoutian A (2007b) An ion channel essential for sensing chemical damage. J Neurosci 27:11412-11415.

Madrid R, de la Peña E, Donovan-Rodriguez T, Belmonte C, Viana F (2009) Variable threshold of trigeminal cold-thermosensitive neurons is determined by a balance between TRPM8 and Kv1 potassium channels. J Neurosci 29:3120-3131. 
Materazzi S, Nassini R, Andrè E, Campi B, Amadesi S, Trevisani M, Bunnett NW, Patacchini R, Geppetti P (2008) Cox-dependent fatty acid metabolites cause pain through activation of the irritant receptor TRPA1. Proc Natl Acad Sci U S A 105:12045-12050.

McNamara CR, Mandel-Brehm J, Bautista DM, Siemens J, Deranian KL, Zhao M, Hayward NJ, Chong JA, Julius D, Moran MM, Fanger CM (2007) TRPA1 mediates formalin-induced pain. Proc Natl Acad Sci U S A 104:13525-13530.

Nagata K, Duggan A, Kumar G, García-Añoveros J (2005) Nociceptor and hair cell transducer properties of TRPA1, a channel for pain and hearing. J Neurosci 25:4052-4061.

Obata K, Katsura H, Mizushima T, Yamanaka H, Kobayashi K, Dai Y, Fukuoka T, Tokunaga A, Tominaga M, Noguchi K (2005) TRPA1 induced in sensory neurons contributes to cold hyperalgesia after inflammation and nerve injury. J Clin Invest 115:2393-2401.

Petrus M, Peier AM, Bandell M, Hwang SW, Huynh T, Olney N, Jegla T, Patapoutian A (2007) A role of TRPA1 in mechanical hyperalgesia is revealed by pharmacological inhibition. Mol Pain 3:40.

Sawada Y, Hosokawa H, Hori A, Matsumura K, Kobayashi S (2007) Cold sensitivity of recombinant TRPA1 channels. Brain Res 1160:39-46.

Schmidt M, Dubin AE, Petrus MJ, Earley TJ, Patapoutian A (2009) Noci- ceptive signals induce trafficking of TRPA1 to the plasma membrane. Neuron 64:498-509.

Story GM, Peier AM, Reeve AJ, Eid SR, Mosbacher J, Hricik TR, Earley TJ, Hergarden AC, Andersson DA, Hwang SW, McIntyre P, Jegla T, Bevan S, Patapoutian A (2003) ANKTM1, a TRP-like channel expressed in nociceptive neurons, is activated by cold temperatures. Cell 112:819-829.

Taylor-Clark TE, Undem BJ, Macglashan DW Jr, Ghatta S, Carr MJ, McAlexander MA (2008) Prostaglandin-induced activation of nociceptive neurons via direct interaction with transient receptor potential Al (TRPA1). Mol Pharmacol 73:274-281.

Trevisani M, Siemens J, Materazzi S, Bautista DM, Nassini R, Campi B, Imamachi N, Andrè E, Patacchini R, Cottrell GS, Gatti R, Basbaum AI, Bunnett NW, Julius D, Geppetti P (2007) 4-Hydroxynonenal, an endogenous aldehyde, causes pain and neurogenic inflammation through activation of the irritant receptor TRPA1. Proc Natl Acad Sci U S A 104:13519-13524.

Wang YY, Chang RB, Waters HN, McKemy DD, Liman ER (2008) The nociceptor ion channel TRPA1 is potentiated and inactivated by permeating calcium ions. J Biol Chem 283:32691-32703.

Zurborg S, Yurgionas B, Jira JA, Caspani O, Heppenstall PA (2007) Direct activation of the ion channel TRPA1 by $\mathrm{Ca}^{2+}$. Nat Neurosci 10:277-279. 